\title{
Formação docente: percepções dos professores sobre o uso das tecnologias móveis digitais no processo de ensino e aprendizagem
}

\author{
Anne Alilma Silva Souza Ferrete ${ }^{1}$, Carla da Conceição Andrade ${ }^{2}$ \\ ${ }^{1}$ Doutorado em Educação. Vice líder do Grupo de Pesquisa NUCA, professora \\ Pesquisadora do Grupo de Pesquisa do NUPIEPED, e do EDaPECI. É professora do \\ Departamento de Educação e do Programa de Pós-Graduação em Educação da \\ Universidade Federal de Sergipe. E-mail: alilma.ferrete50@gmail.com. Departamento \\ de Educação - Universidade Federal de Sergipe. Av. Marechal Rondon, s/n, Jd. Rosa \\ Elze. São Cristóvão/SE. CEP 49100-000. \\ ${ }^{2}$ Pró-Reitoria de Ensino - Instituto Federal de Sergipe. R. Francisco Portugal, 150 - \\ Salgado Filho, Aracaju - SE, 49020-390. \\ \{alilma.ferrete50\}@gmail.com, \{ccandrade01\}@gmail.com

\begin{abstract}
This paper seeks to understand the teachers' perceptions about teacher education for the use of digital mobile information and communication technologies (TMDIC) in the teaching and learning process. For that, an evaluation was carried out among education professionals enrolled in the discipline Special Topics of Teaching: Digital Technologies of Information and Communication and Teaching Training, offered by the Graduate Program in Education of UFS. The research was conducted intentionally, then the content was analyzed. The results demonstrate that the discipline aroused interest in the use of TMDIC, based on the planning of pedagogical actions and critical reflection.
\end{abstract}

Resumo. Este trabalho busca compreender as percepções dos professores sobre a formação docente para o uso das tecnologias móveis digitais de informação e comunicação (TMDIC) no processo de ensino e aprendizagem. Para tanto, realizou-se uma avaliação entre profissionais da Educação matriculados na disciplina Tópicos Especiais de Ensino: Tecnologias Digitais de Informação e Comunicação e a Formação Docente, ofertada pelo Programa de Pós-graduação em Educação da UFS. A pesquisa foi realizada de forma intencional, em seguida, fez-se análise do conteúdo. Os resultados demonstram que a disciplina despertou o interesse para o uso das TMDIC, embasado no planejamento das ações pedagógicas e na reflexão crítica.

\section{Introdução}

O presente trabalho busca compreender as percepções dos professores sobre a formação docente para a execução das tecnologias móveis digitais de informação e comunicação (TMDIC) no processo de ensino e aprendizagem. Nesse sentido, o trabalho apresenta os resultados de uma avaliação aplicada entre profissionais da Educação matriculados na disciplina Tópicos Especiais de Ensino: Tecnologias Digitais de Informação e Comunicação e a Formação Docente. A disciplina é ofertada de forma optativa pelo 
Programa de Pós-Graduação em Educação, da Universidade Federal de Sergipe, para alunos dos níveis de Mestrado e Doutorado, além de alunos graduados que não possuem vínculo com a instituição, mas demonstram interesse em participar do processo seletivo, os chamados alunos especiais.

O trabalho está estruturado em três seções, além da introdução e das considerações finais. $\mathrm{Na}$ primeira, discute-se a inserção das tecnologias digitais na Educação brasileira. Em seguida, é apresentada uma descrição da disciplina, com os seus objetivos e metodologia. A terceira seção trata dos procedimentos da pesquisa, com a definição da amostragem e a apreciação dos dados, de acordo com o método escolhido, a análise de conteúdo. Por último, são elencados os resultados da pesquisa.

\section{As tecnologias digitais na Educação brasileira}

A difusão do computador pessoal e da internet no final do século XX provocou intensas transformações nas relações sociais. Castells (1999) defende esse momento da nossa história como um "intervalo cuja característica é a transformação de nossa cultura material pelos mecanismos de um novo paradigma tecnológico que se organiza em torno da tecnologia da informação" [Castells 1999 p. 67].

O impacto causado pelo avanço tecnológico modifica o habitus de nossa sociedade e isso já é percebido na Educação. Pais e professores denunciam a falta de interesse de nossos jovens pela escola, enquanto estes demonstram que existem outras maneiras de produzir e adquirir informações e ter maior autonomia. $\mathrm{O}$ aluno do século XXI está inserido cada vez mais no mundo virtual. As redes sociais, os jogos, as simulações, tudo o que está na rede parece ser mais atraente para o jovem do que o professor e a velha sala de aula. Preparar a escola para a integração das tecnologias móveis digitais de informação e comunicação em seu cotidiano é um dos grandes desafios que a Educação enfrenta.

Esse processo, todavia, não é fácil. A presença da tecnologia no ambiente escolar lança novos desafios, exigindo uma estrutura física adequada, que proporcione acesso de qualidade à rede e formação de professores e gestores, para que a tecnologia faça parte da cultura escolar. Como afirma Ferrete e Teixeira (2015), é preciso ter a "tecnologia realmente integrada ao currículo escolar, com o objetivo de promover a cultura digital na instituição" [Ferrete and Teixeira 2015 p. 285].

No Brasil, desde as últimas décadas do século passado, o Governo Federal, através do Ministério da Educação, institui políticas e programas educacionais para a inserção tecnológica no ambiente escolar. Políticas e programas como o Proinfo, TV Escola e Portal do Professor destacam-se em meio às iniciativas mais eficazes.

Mais recentemente, o MEC instituiu novas políticas educacionais que se caracterizaram por duas vertentes. A primeira política consistiu na distribuição de equipamentos móveis digitais para professores e alunos, além da capacitação dos docentes para o uso da tecnologia móvel digital, por intermédio do programa Um Computador por Aluno e do Tablet Educacional. A segunda baseou-se no fomento à Educação em tempo integral e na reestruturação do currículo, a partir de ações pedagógicas que possibilitassem, entre outros temas, o fortalecimento da cultura digital no ambiente escolar. É o caso dos programas Mais Educação e Ensino Médio Inovador.

Os esforços demandados pelo governo visando à transformação da cultura escolar para o uso das TDICs, todavia, têm surtido pouco efeito. Vale lembrar que a 
inserção das tecnologias digitais na escola não deve se pautar apenas para aquisição de equipamentos. A fim de vivenciar efetivamente a cultura digital, é necessário pensar e agir em rede. No caso da Educação, a rede é formada por diversos pontos: estrutura física e elétrica, conexão com internet, currículo, formação pedagógica inicial e continuada. Se esses pontos não estiverem interconectados, a cultura digital continuará sem fazer parte do ambiente escolar.

Em pesquisa recente, a pesquisadora Simone Lucena (2016) faz um alerta sobre as políticas nacionais de fomento às tecnologias na Educação. Para a autora:

[...] a inserção das tecnologias na escola ocorreu muito mais por uma pressão do mercado da informática para a compra de equipamentos do que por uma real necessidade da comunidade escolar [Lucena 2016 p. 285].

Diante do exposto, percebemos que a tecnologia digital penetrou o ambiente escolar, tanto por meio das políticas públicas quanto pelas mãos dos alunos e professores com os tablets, notebooks e smartphones. Precisamos incorporá-la ao processo educativo. Um passo fundamental para que isso aconteça é procurar promover a formação dos profissionais da Educação para o uso das TMDICs.

\section{TMDIC e formação docente}

Como foi destacado anteriormente, este trabalho apresenta os resultados da avaliação da disciplina Tópicos Especiais de Ensino: Tecnologias Digitais de Informação e Comunicação e a Formação Docente. A disciplina foi ofertada de forma optativa pelo Programa de Pós-Graduação em Educação da Universidade Federal de Sergipe no primeiro semestre de 2017 e contou com a participação de sete alunos. Todos os discentes matriculados têm formação na área educacional ainda que de forma diversa: Pedagogia, Letras, História, Sociologia, Educação Física e Química.

A disciplina teve como objetivos: estudar, refletir e analisar o movimento teoriaprática na utilização das tecnologias móveis digitais de informação e comunicação na Educação; promover discussão a respeito do uso na Educação das tecnologias digitais e da conexão com outras tecnologias; abordar o uso de novas e antigas tecnologias de forma interdisciplinar no ambiente educativo e na formação dos professores; além de vivenciar e produzir situações práticas que propiciem aos alunos refletir criticamente sobre o uso das tecnologias móveis digitais de comunicação e informação na Educação, de suas possibilidades e limites.

Para cumprir tais objetivos, a disciplina foi estruturada em duas etapas. A primeira correspondeu a uma reflexão teórica sobre a presença das tecnologias digitais no processo educativo e a importância da formação docente para o uso das TMDIC. A segunda, consistiu no desenvolvimento de situações práticas acerca do uso das TMDIC em sala de aula. Dessa forma, todos os alunos puderam expor suas impressões sobre a cibercultura e a Educação, analisar de que maneira esse processo vem acontecendo no Brasil e vivenciar a experiência do que e de como ensinar, em uma realidade permeada pelo mundo virtual.

A disciplina teve uma carga horária de sessenta horas distribuídas em aulas de quatro horas, durante quinze semanas. Nesse período, foram realizados debates, seminários, artigos, elaboração e execução de aula com uso de softwares, aplicativos e objetos virtuais de aprendizagem. Além dessas atividades, o debate sobre os temas 
elencados em sala de aula se prolongava por meio do aplicativo WhatsApp, utilizado como fórum de discussão da turma. Nesse ambiente virtual, eram depositados vídeos, podcasts, artigos e livros digitais, informes sobre eventos relacionados à temática.

A utilização do WhatsApp como fórum de discussão foi fundamental para a dinâmica das aulas, visto que proporcionou um clima de colaboração entre os alunos e professor, como também estendeu o espaço e o tempo de sala de aula. É importante ressaltar esse aspecto, pois diversos alunos da turma moravam ou trabalhavam em municípios diferentes e até em estados diferentes, porém, mesmo assim, durante o tempo em que a disciplina foi ministrada, todos os alunos estavam interconectados, discutindo, construindo e compartilhando informações em todos os momentos, além de poder tirar dúvidas, o que acabou constituindo como apoio pedagógico para além da sala de aula, e isso muito contribui para a construção do conhecimento.

Ao final da disciplina, aplicou-se entre os alunos um questionário de avaliação, elaborado através do software Google Forms, e o link foi disponibilizado pelo grupo da turma no WhatsApp. O objetivo da avaliação era identificar as percepções dos alunos sobre a metodologia da disciplina e se o conhecimento adquirido naquele momento seria perpetuado em suas atividades profissionais, já que todos são professores de formação e atuam em sala de aula ou em outras atividades educativas.

$\mathrm{O}$ questionário foi composto por treze questões, entre perguntas abertas e fechadas. Estava organizado em três seções: apresentação do instrumento, com o propósito de evidenciar aos participantes os motivos que levaram a elaboração do questionário; identificação do aluno e interesse pela disciplina, visando identificar as características do grupo investigado; e avaliação dos objetivos e das práticas desenvolvidas, com o intuito de medir as variáveis dos fenômenos atitudinais relacionados às práticas docentes com o uso das TMDIC.

Para analisar os dados obtidos com o questionário, optou-se por fazer uma análise do conteúdo, conforme a definição:

[...] conjunto de técnicas de análise das comunicações visando obter, através de procedimentos sistemáticos e objetivos de descrição do conteúdo das mensagens, indicadores (quantitativos ou não) que permitam inferir conhecimentos relativos às condições de produção/recepção (variáveis inferidas) dessas mensagens. [Bardin apud Richardson, 1999, p. 223]

Corroborando com o autor, vale destacar que os procedimentos realizados a partir desse conjunto de técnicas, bem como os resultados obtidos, encontram-se descritos na próxima seção.

\section{Procedimentos metodológicos e análise dos dados}

Para uma melhor compreensão das etapas desenvolvidas na pesquisa e dos resultados obtidos, torna-se necessária a descrição dos participantes pesquisados. Apresentamos a identificação na tabela abaixo: 
VI Congresso Brasileiro de Informática na Educação (CBIE 2017)

Anais dos Workshops do VI Congresso Brasileiro de Informática na Educação (WCBIE 2017)

\begin{tabular}{cl}
\multicolumn{2}{c}{ Alunos matriculados na Disciplina Tópicos Especiais de Ensino: TDIC e a Formação } \\
Docente
\end{tabular}

Fonte: próprios autores.

A tabela acima evidencia as características homogêneas e, ao mesmo tempo, diversas da turma. Todos os alunos são licenciados, mas em áreas distintas, atuam na Educação, sendo que a maioria está em sala de aula, ou seja, Educação formal. Apenas um aluno atua na Educação não formal, desempenhando a função de personal training. Todos estão vinculados ao programa de Pós-graduação em Educação de diversas maneiras: em nível de Mestrado, Doutoramento ou Especial. São profissionais que atuam nos diversos níveis de ensino: fundamental, médio e superior. Chama a atenção o fato de os alunos trabalharem em municípios diferentes, o que possibilitou a disciplina abordar contextos e realidades diferentes.

Feita a identificação da amostra, seguiremos com a análise dos dados. Portanto, estabeleceu-se como indicadores: aquisição de conhecimentos e prática pedagógica. Definiu-se ainda a unidade de registro. Neste caso, preferiu-se realizar um recorte de palavra, enquanto menor unidade de registro. A categoria de palavras escolhida foi o verbo, pois, no sentido semântico, representa ação, processo ou estado. Selecionado o recorte, estabeleceu-se a contagem das unidades de registro. Foram identificados 53 verbos ou locuções verbais diferentes ao longo das respostas. Os verbos foram editados para o modo infinitivo e relacionados de acordo com a frequência em que apareceram.

A categorização dos dados foi realizada segundo os indicadores. Assim, a partir das unidades de registro, foram estabelecidas duas categorias: aquisição de conhecimento sobre TMDIC e uso das TMDIC na prática pedagógica. Cada resposta ao questionário foi separada em dois grupos, correspondendo cada grupo a uma categoria, independentemente do enunciado. O grupo aquisição de conhecimentos sobre TMDIC

\footnotetext{
${ }^{1} \mathrm{Na}$ tabela, estão listados seis alunos em um universo de sete alunos. A sétima aluna foi excluída da amostra por se tratar de uma das autoras responsáveis pela pesquisa.
} 
VI Congresso Brasileiro de Informática na Educação (CBIE 2017)

Anais dos Workshops do VI Congresso Brasileiro de Informática na Educação (WCBIE 2017)

foi composto por 19 verbos. O grupo uso das TMDIC na prática docente foi composto por 34 verbos. O texto produzido em cada grupo categorial foi lido cuidadosamente, sempre comparando as respostas individuais de cada aluno.

Relação de verbos identificados nas respostas do formulário, organizados segundo os indicadores

\begin{tabular}{|c|c|c|c|}
\hline \multicolumn{2}{|c|}{$\begin{array}{c}\text { Aquisição e conhecimento sobre } \\
\text { TMDIC }\end{array}$} & \multicolumn{2}{|c|}{ Uso das TMDIC na prática pedagógica } \\
\hline Verbo & $\begin{array}{c}\text { Quantidade no } \\
\text { formulário }\end{array}$ & Verbo & $\begin{array}{l}\text { Quantidade no } \\
\text { formulário }\end{array}$ \\
\hline & & Usar & 10 \\
\hline & & Utilizar & 05 \\
\hline & & Despertar & 04 \\
\hline Aprender & 06 & Mostrar & 03 \\
\hline & & $\begin{array}{l}\text { Exigir; Fazer; } \\
\text { Interagir; Montar; } \\
\text { Produzir; Rever }\end{array}$ & 02 \\
\hline $\begin{array}{l}\text { Abordar; Ampliar; } \\
\text { Problematizar; } \\
\text { Apresentar; Buscar; } \\
\text { Discutir; Refletir. }\end{array}$ & 02 & $\begin{array}{c}\text { Ajudar; Atender: } \\
\text { Buscar; Construir; } \\
\text { Deixar; } \\
\text { Desenvolver; } \\
\text { Diferenciar; } \\
\text { Dinamizar; } \\
\text { Envolver; Escolher; } \\
\text { Estimular; Incluir; } \\
\text { Motivar; Oferecer; } \\
\text { Possibilitar; } \\
\text { Potencializar; } \\
\text { Preparar; } \\
\text { Promover; } \\
\text { Proporcionar; } \\
\text { Realizar; } \\
\text { Relacionar; } \\
\text { Revisar; } \\
\text { Solidificar; Tornar. }\end{array}$ & 01 \\
\hline
\end{tabular}

Fonte: próprios autores.

\subsection{Aquisição de conhecimento sobre as TDIC}

Essa categoria engloba tudo o que foi percebido sobre teorias, conceitos, definições, reflexões, análises, estudos e debates presentes na fala dos alunos. São as concepções epistemológicas existentes nas pesquisas e na formação que eles trazem ou adquirem 
VI Congresso Brasileiro de Informática na Educação (CBIE 2017)

Anais dos Workshops do VI Congresso Brasileiro de Informática na Educação (WCBIE 2017)

em sala de aula. É a categoria que motiva a matrícula de todos os pesquisados nesta disciplina:

-Interesse sobre o tema, devido ao meu objeto de pesquisa. (Aluna A)

- Aprofundar o conhecimento nessa possibilidade pedagógica (TDIC), sobretudo por familiarizar-se com o objeto de estudo pretendido para o Mestrado (Mídia-Educação). (Aluno F)

Os alunos escolhem a disciplina porque o tema dela está relacionado ao que pesquisam ou pretendem pesquisar. Possuem o desejo de adquirir subsídios teóricosmetodológicos para discorrer sobre o objeto de estudo, as tecnologias digitais na Educação. Nas falas, não se identifica a possibilidade de melhorar as práticas pedagógicas, ou o processo de ensino e aprendizagem, visto que todos os alunos são professores de formação e que desempenham atividades ligadas a esta área.

$\mathrm{O}$ fato de o discurso dos pesquisados ligar-se à atividade de pesquisa e não à docência pode ser justificado pelo lugar em que a disciplina acontece, um programa de Pós-graduação de uma universidade. Este é o lugar da produção do conhecimento. Todavia, além da pesquisa, a Pós-graduação é uma atividade de formação continuada, na qual se espera que os profissionais saiam mais qualificados.

A preocupação com a aquisição de conhecimentos ainda esteve presente com o desenvolvimento das atividades propostas pela disciplina. Temas como Educação a distância e ambientes virtuais de aprendizagem e o Uso das tecnologias digitais a partir de aplicativos e objetos virtuais foram discutidos e vivenciados em sala. Ao serem questionados sobre essas atividades, alguns alunos demonstraram a preocupação com a pesquisa para o bom desempenho delas:

- Foi interessante, pois me levou a pesquisar e estudar sobre os aplicativos da área de Educação em Química. (Aluno D).

-Sim. Oferecendo aos meus alunos as possibilidades metodológicas dos recursos virtuais. (Aluna E).

A aluna E chama a atenção por ser professora atuante no Ensino Superior. Quando questionada se pretende utilizar objetos virtuais em sua prática pedagógica, ela reforça que irá utilizar, não para fazer o aluno aprender por meio do objeto, mas como um conteúdo a mais a ser trabalho em sala de aula.

A concepção de conhecimento adquirido está ainda na última pergunta do questionário: "Você pretende participar de outra atividade de capacitação docente para o uso pedagógico das TDIC? Por quê?"

-Sim, porque ainda há muito o que aprender. (Aluna B).

- Sim, para ampliar meus conhecimentos. (Aluno E).

-Sim, porque tudo que é informação sobre as TDIC vai somar na minha capacitação profissional e pessoal. (Aluna F).

Acerca das respostas acima relacionadas, podemos desenvolver algumas proposições. A primeira é que é forte o anseio desses alunos/profissionais da Educação em aprender cada vez mais sobre as TDIC. A temática é recente como campo de pesquisa e a rapidez com que as tecnologias avançam exige dos profissionais que sempre se atualizem. Basta apenas aprender mais? Essa é a segunda proposição. O aprendizado necessita estar integrado à pratica. Aprender para desenvolver pesquisa sobre o tema e melhorar a prática pedagógica, não somente para saber mais. A terceira proposição corresponde à postura dos alunos ao final do curso: sabemos que o interesse 
VI Congresso Brasileiro de Informática na Educação (CBIE 2017)

Anais dos Workshops do VI Congresso Brasileiro de Informática na Educação (WCBIE 2017)

em aprender sobre as TDIC para desenvolver pesquisa, ou seja, aprender mais, foi o que motivou a matrícula dos alunos na disciplina. Após um semestre, os alunos continuaram relacionando formação continuada sobre TDIC a aprender mais, adquirir conhecimentos. Vejamos o que informam os dados sobre prática pedagógica.

\subsection{Uso das TDIC na prática pedagógica}

Se os dados da categoria anterior mostraram que os alunos se matricularam na disciplina TDIC e formação docente como forma de aquisição de conhecimentos, os dados desta categoria irão apresentar o que realmente os alunos absorveram em quinze semanas de aula. A quantidade e a intensidade dos verbos já dizem muito sobre as duas categorias. É o caso do verbo utilizar e seu sinônimo usar que tiveram maior intensidade nas respostas:

- Por ser uma disciplina que envolve o uso da tecnologia nas escolas e por ser um conteúdo atual. (Aluna $\mathrm{C}$ ).

-Todos os cursos solidificaram a minha vontade de utilizar as tecnologias digitais como um instrumento potencialmente capaz de dinamizar as aulas e promover novas aprendizagens. (Aluna B).

-Sim, na utilização, com maior propriedade de objetos virtuais. (Aluna E).

- Sim. Para usar na minha prática pedagógica. (Aluna A).

Os verbos usar e utilizar ou os substantivos derivados destas palavras estão em todas a falas acima relacionados a tecnologias digitais em sala de aula. Isso demonstra que, ao longo da disciplina, alunos começaram a compreender que a aprendizagem sobre TMDIC na Educação não é meramente aprender conteúdos, mas aprender a integrar as tecnologias ao currículo, em suas práticas pedagógicas, modificando o processo de ensino e aprendizagem.

Quando as TMDIC estão integradas ao currículo, as ações pedagógicas com o uso das tecnologias são planejadas, de maneira que os professores possam estimular seus alunos à reflexão crítica sobre as alterações causadas nas relações sociais em decorrência da cultura digital. Esse é o caminho que as formações sobre TMDIC e cultura digital necessitam trilhar. Os alunos/profissionais de Educação perceberam isso ao longo da disciplina.

- Foi uma experiência importante pois nos mostrou o processo de escolha do aplicativo a partir de sua capacidade de atender aos objetivos que se quer alcançar. (Aluna B).

- Foi muito interessante esse exercício de montar uma estratégia para utilizar um objeto de aprendizagem e um aplicativo dialogando com o assunto de sua área de atuação. (Aluno F).

O desenvolvimento das situações práticas acerca do uso das TMDIC em sala de aula pelos alunos evidenciou a importância da elaboração de ações pedagógicas planejadas que assegurassem "a unidade e a coerência do trabalho docente". [Libâneo apud Behar 2013 p. 181].

As situações vivenciadas refletem no discurso dos alunos. A relevância das palavras utilizar e usar associadas às TMDIC na prática pedagógica ou a percepção da necessidade do planejamento para a execução das atividades docentes são exemplos de como, ao longo da disciplina, os alunos mudaram a perspectiva sobre o curso. Não desejavam apenas aquisição de conhecimento, mas perceberam a importância de relacionar o aprendizado para aperfeiçoar a prática pedagógica. 
Assim, elegeram como objetivo da disciplina que teve maior contribuição para a formação: vivenciar e produzir situações práticas que propiciem aos alunos refletir criticamente sobre o uso das tecnologias móveis digitais de comunicação e informação na Educação, de suas possibilidades e limites.

A escolha desse objetivo exemplifica a mudança de perspectivas que a disciplina possibilitou aos alunos. Se, no momento da matrícula, a escolha por uma disciplina que versava sobre Tecnologia e Educação contribuiria para aprofundar os conhecimentos relativos à pesquisa acadêmica, ao final do curso, eles compreenderam que o aperfeiçamento da prática docente, através da reflexão, do planejamento e do desenvolvimento de ações pedagógicas contribui não apenas para o desempenho da pesquisa, como também para o aperfeiçoamento profissional de cada aluno.

\section{Considerações Finais}

Este trabalho buscou compreender as percepções dos professores sobre a formação docente para o uso das tecnologias móveis digitais, através da aplicação de um questionário com profissionais da Educação matriculados numa disciplina de Pósgraduação da UFS. Como resultado, percebeu-se que, inicialmente, os alunos escolheram cursar uma disciplina sobre formação docente e TDIC com o propósito de adquirir conhecimento sobre a temática. Entretanto, ao longo da disciplina, os alunos perceberam a importância de planejar atividades pedagógicas que os estimulassem a refletirem criticamente sobre o uso das tecnologias digitais.

A disciplina Tópicos Especiais de Ensino: Tecnologias Digitais de Informação $e$ Comunicação e a Formação Docente permitiu que os alunos matriculados ampliassem o arcabouço teórico sobre tecnologias digitais na Educação, refletissem sobre o uso pedagógico das tecnologias e fortalecessem as práticas pedagógicas enquanto profissionais da Educação, a partir do planejamento das ações e da aplicação de atividades criativas correspondendo ao avanço tecnológico que está em curso.

\section{References}

Bardin, L. (2011) “Análise de conteúdo”, Edições 70, São Paulo.

Behar, P. A. (2013) “Competências em Educação a distância”, Penso, Porto Alegre.

Castells, M. (1999) “A sociedade em rede - a era da informação: economia, sociedade e cultura", vol. 1, Paz e Terra, São Paulo.

Ferrete, A. A. S. S. Teixeira, R. D. (2015) "Formação de educadores: reflexões sobre o uso dos computadores portáteis na escola", In Lições do projeto um computador por aluno: estudos e pesquisas no contexto da escola pública, Organizado por José Aires de Castro Filho, Maria Auricélia da Silva and Dennys Leite Maia., EDUECE, Ceará, p. 280-301.

Richardson, R. J. (2008) “Pesquisa social: métodos e técnicas”, Atlas, São Paulo.

Levy, P. (1999) “Cibercultura”, Edições Loyola, São Paulo, 2a edição. 